\title{
The size of the auroral belt during magnetic storms
}

\author{
N. Yokoyama ${ }^{1}$, Y. Kamide ${ }^{1}$, and H. Miyaoka ${ }^{2}$ \\ ${ }^{1}$ Solar-Terrestrial Environment Laboratory, Nagoya University, Toyokawa 442, Japan \\ ${ }^{2}$ National Institute of Polar Research, Tokyo 173, Japan
}

Received: 25 August 1997 / Revised: 26 November 1997 / Accepted: 4 December 1997

\begin{abstract}
Using the auroral boundary index derived from DMSP electron precipitation data and the Dst index, changes in the size of the auroral belt during magnetic storms are studied. It is found that the equatorward boundary of the belt at midnight expands equatorward, reaching its lowest latitude about one hour before $D s t$ peaks. This time lag depends very little on storm intensity. It is also shown that during magnetic storms, the energy of the ring current quantified with $D s t$ increases in proportion to $L_{e}^{-3}$, where $L_{e}$ is the $L$ value corresponding to the equatorward boundary of the auroral belt designated by the auroral boundary index. This means that the ring current energy is proportional to the ion energy obtained from the earthward shift of the plasma sheet under the conservation of the first adiabatic invariant. The ring current energy is also proportional to $E_{m a q}$, the total magnetic field energy contained in the spherical shell bounded by $L_{e}$ and $L_{e q}$, where $L_{e q}$ corresponds to the quiet-time location of the auroral precipitation boundary. The ratio of the ring current energy $E_{R}$ to the dipole energy $E_{\text {mag }}$ is typically $10 \%$. The ring current leads to magnetosphere inflation as a result of an increase in the equivalent dipole moment.
\end{abstract}

Key words. Ionosphere (Auroral ionosphere) · Magnetospheric physics (Auroral phenomena; storms and substorms)

\section{Introduction}

During the last two decades, a series of extensive statistical studies have shown that the auroral belt expands/contracts in latitude systematically, responding

Correspondence to: Y. Kamide to geomagnetic activity as well as changes in the interplanetary magnetic field (IMF) and the solar wind (e.g., Kamide and Winningham, 1977; Hardy et al., 1981; Makita and Meng, 1984). In particular, the southward component of the IMF has been found to be the main contributor to the size of the auroral belt (e.g., Nakai et al., 1986). On the other hand, changes in the Dst index, which have commonly been used to identify geomagnetic storms, are highly correlated with southward turnings of the IMF (Kokubun, 1972; Russell et al., 1974; Burton et al., 1975; Gonzalez et al., 1994). It is thus natural to expect that the auroral belt expands significantly during the main phase of magnetic storms.

Based on the equatorward boundary of the auroral luminosity, the latitudinal shift of the auroral belt during intense storms has been studied by Akasofu and Chapman (1963) and Akasofu (1964). The equatorward shift of the auroral belt has in fact been closely associated with the development of geomagnetic storms, i.e., decreases in the Dst index, although their study is limited to only a few individual storms. It is also well known that during very intense magnetic storms, the auroral belt shifts to what is normally considered to be sub-auroral latitudes or even mid-latitudes (e.g., Tinsley et al., 1986; Allen et al., 1989; Rassoul et al., 1992; Shiokawa et al., 1996). There have been, however, no quantitative, as well as statistical, studies regarding the relationship between the size of the auroral belt and the intensity of geomagnetic storms, because it is intrinsically difficult to differentiate the substorm and storm effects in terms of the location of auroras. During the main phase of a magnetic storm, which is associated with southward IMF, intense substorms occur successively. It is under debate whether the storm-time ring current develops due to sustained, southward IMF or due to frequent occurrence of substorms (Kamide, 1992; Gonzalez et al., 1994).

The purpose of the present work is to address the following questions which were not answered clearly in the earlier studies: 
1. What is the quantitative relationship between the size of the auroral belt and the ring current intensity during magnetic storms?

2. Does the equatorward shift of the auroral belt occur simultaneously with an increase in the ring current? If not, what does the time lag imply in terms of magnetosphere-ionosphere coupling?

3. Is the relationship between these two quantities during the storm main phase different from that during the recovery phase?

\section{Data}

We used the auroral boundary index and the Dst index from 1983 to 1991. The 1-h resolution Dst index (see Sugiura and Kamei, 1991) is derived from magnetic variations at mid-latitudes, which are caused primarily by the ring current in the magnetosphere. Note that the Dst index includes the effects of the magnetopause and magnetotail currents as well. The ring current is known to consist of the symmetric and partial ring currents, but Dst represents, by definition, only the symmetric part of the ring current, which is enhanced significantly during geomagnetic storms.

Based on the Dst index, we visually identified 423 geomagnetic storms, and divided them into three categories: intense, moderate, and weak storms, according to the classification in earlier studies (e.g., Sugiura and Chapman, 1960; Taylor et al., 1994; Loewe and Prölss, 1997; Yokoyama and Kamide, 1997). Dst values are known to be proportional to the total energy of the ring current in the magnetosphere (Dessler and Parker, 1959; Sckopke, 1966).
Details on the concept and the practical procedure of analyzing the auroral boundary index are described in Gussenhoven et al. (1981, 1983). This index is derived from electron precipitation data of the DMSP satellites and is given in corrected geomagnetic latitude. It quantifies the location of the equatorward boundary of the diffuse auroral precipitation at midnight. When satellite measurements are not made in the midnight sector, the index is calculated from evening sector observations by employing an extrapolation in MLT (magnetic local time) through the statistical linear relationship between the boundary value and the $K_{p}$ index.

The orbital period of each of the DMSP satellites is $101 \mathrm{~min}$, encompassing two evening sector boundaries. There is therefore one index value, on average, every 50 min for each satellite. Since two satellites (DMSP F2 and F4) were used to derive the index which has been used in the present study, its time resolution is 2 per 50 minutes during periods of good data acquisition.

\section{Results}

\subsection{Equatorward shift of the auroral boundary index}

Figure 1, based on one-month data, illustrates how the auroral boundary index responded to Dst in March 1989, during which a major storm occurred on March 13 and 14 , reaching nearly $-600 \mathrm{nT}$ in Dst (Allen et al., 1989). It is seen that when the Dst value is larger than $-50 \mathrm{nT}$, the boundary index is in general between $65^{\circ}$ and $55^{\circ}$ in corrected geomagnetic latitude. Once the Dst index decreases beyond $-100 \mathrm{nT}$, however, the auroral belt moved equatorward dramatically, to below $50^{\circ}$.

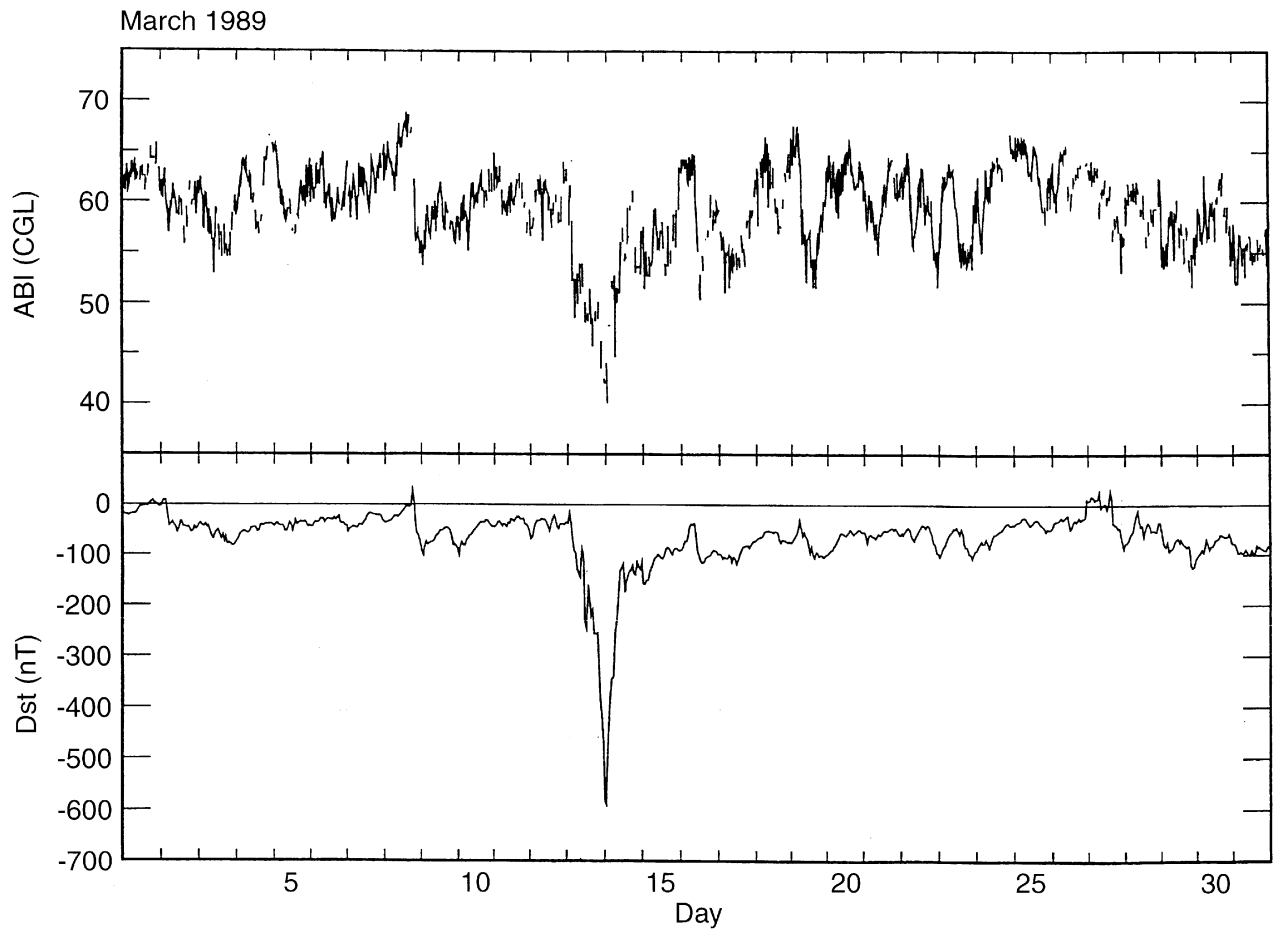

Fig. 1. Time variations of the auroral boundary index and the $D s t$ index for March 1989. The horizontal axis shows the day of month. The top panel is for the auroral boundary index and the bottom panel is for the Dst index 
That is, the relationship between the two indices is nonlinear.

In order to examine their relationship more quantitatively, we have selected minimum values of the $D s t$ index (at the peak of magnetic storms) and of the corresponding auroral boundary index. We have noticed that during individual geomagnetic storms, the time when the auroral boundary reached the lowest latitude differs from that when the Dst index reached the minimum value. Figure 2 shows the time difference between the auroral boundary peak and the Dst peak $\left(=D s t_{\text {min }}\right)$; that is $t_{D}-t_{A}$, where $t_{A}$ and $t_{D}$ represent the times of the boundary index peak and the Dst minimum, respectively. The four panels in Fig. 2 show four histograms of the time difference for three different categories of storm intensity: 133 weak storms $\left(D s t_{\text {min }} \geq-50 \mathrm{nT}\right), \quad 205$ moderate storms $(-50>$ $\left.D s t_{\min } \geq-100 \mathrm{nT}\right)$, and 85 intense storms (Dst $t_{\text {min }}$ $<-100 \mathrm{nT})$, as well as for all 423 storms. More than one value, often three, per hour are available for the auroral boundary index. To be compatible with $D s t$, a unit bin of one hour has been chosen.

In all four panels, the equatorward boundary of the auroral belt appears to reach the lowest latitude $0-2 \mathrm{~h}$ before Dst reaches its peak, although the deviation is higher for more intense storms. It is also evident that
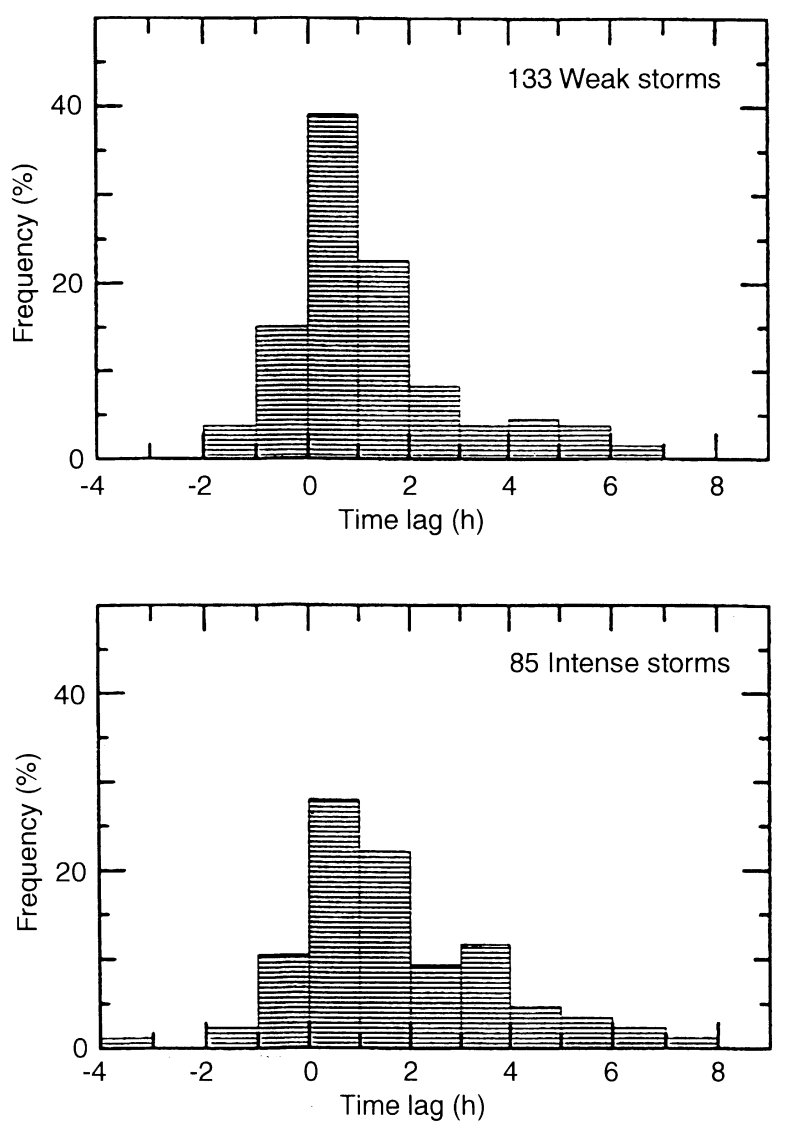

Fig. 2. The time lag $t_{D}-t_{A}$, where $t_{A}$ and $t_{D}$ show the times of the lowest latitude of the auroral boundary and of the minimum Dst, respectively. The four panels show the histograms for different storm categories: weak storms $\left(D s t_{\text {min }} \geq-50 \mathrm{nT}\right)$, moderate storms this time delay is independent of the minimum Dst value, i.e., the magnitude of magnetic storms.

In the following, the Dst index is transformed into the energy of the ring current, so that it is possible to discuss how the auroral belt expands equatorward in association with changes in the ring current energy and the corresponding magnetospheric configuration. Dessler and Parker (1959) related the Dst index to the energy of the ring current $E_{R}$ using the simple expression

$\frac{D s t}{B_{0}}=-\frac{2 E_{R}}{3 E_{m}}$

where $B_{0}\left(=3 \times 10^{4} \mathrm{nT}\right)$ represents the horizontal component of the Earth's magnetic induction and $E_{m}\left(=8 \times 10^{17} \mathrm{~J}\right)$ represents the total energy of the magnetic field external to the Earth. This leads to

$E_{R}=-4 \times 10^{13}$ Dst.

Since processes in the near-Earth magnetosphere are the subject of this study, we introduce the $L$-value which corresponds to the latitude of the electron precipitation boundary. Assuming that the inner magnetosphere is configured as a dipole, the latitude $\Lambda$ and the corresponding $L$-value, $L_{e}$, are expressed as
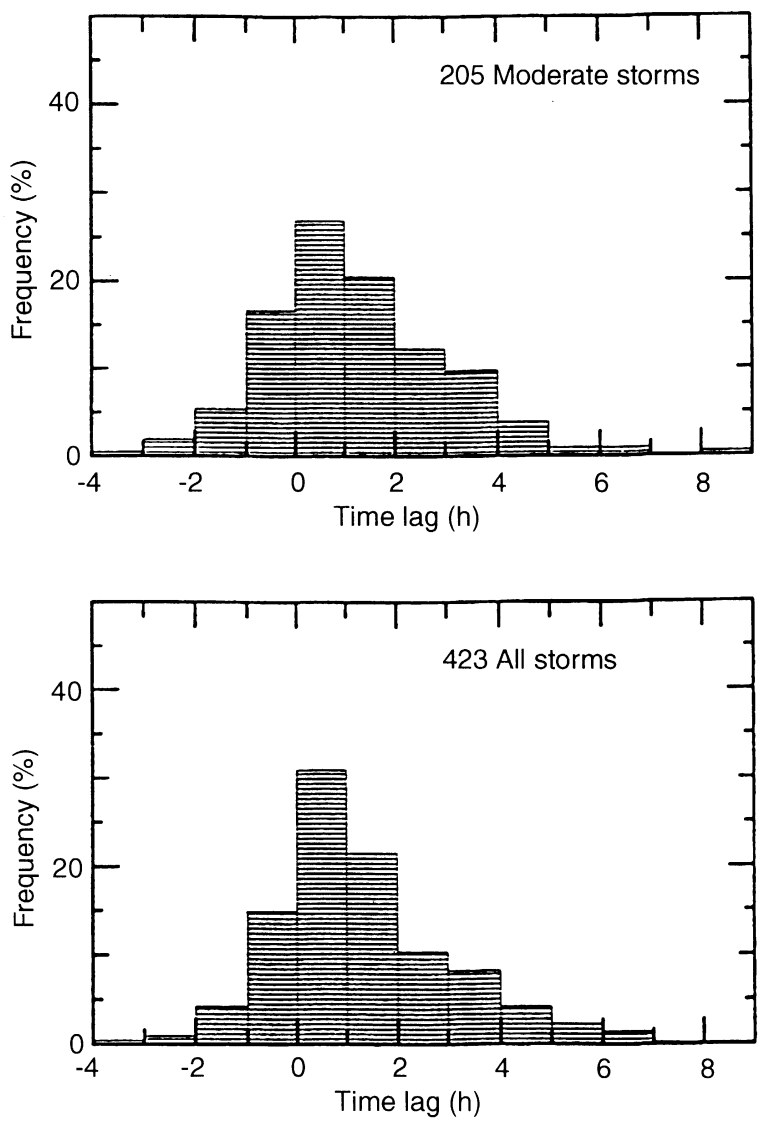

$\left(\left(-50>D s t_{\min } \geq-100 \mathrm{nT}\right)\right.$ intense storms $\left(D s t_{\min }<-100 \mathrm{nT}\right)$, and all storms, where $D s t$ is the minimum $D$ st. The horizontal axis shows the time lag in hours and the vertical axis (the occurrence frequency) is in percentage for each category 


$$
L_{e}=\frac{1}{\cos ^{2} \Lambda}
$$

The top panel of Fig. 3 shows the equatorward boundary of the auroral belt, i.e. the auroral boundary index, and the Dst index for all 423 storms in our database covering the period from 1983 to 1991 . For the same data set, the bottom panel shows $L_{e}$ obtained by Eq. (3) and the energy of the ring current estimated from Eq. (2). Although, as shown in Fig. 2, the boundary index tends to reach the equatorwardmost location approximately one hour ahead of the corresponding Dst peak during individual storms, the statistical result of the correlation between Dst and the boundary index at the time of the Dst peak (not shown here) is similar to that indicated in Fig. 3. We will, therefore, use the relationship between the two peak values for the following statistical analysis.

The $L_{e}-E_{R}$ diagram (the bottom panel of Fig. 3) shows that for the electron boundary to shift more earthward, more ring current energy is required. It appears that the energy gain of the ring current is
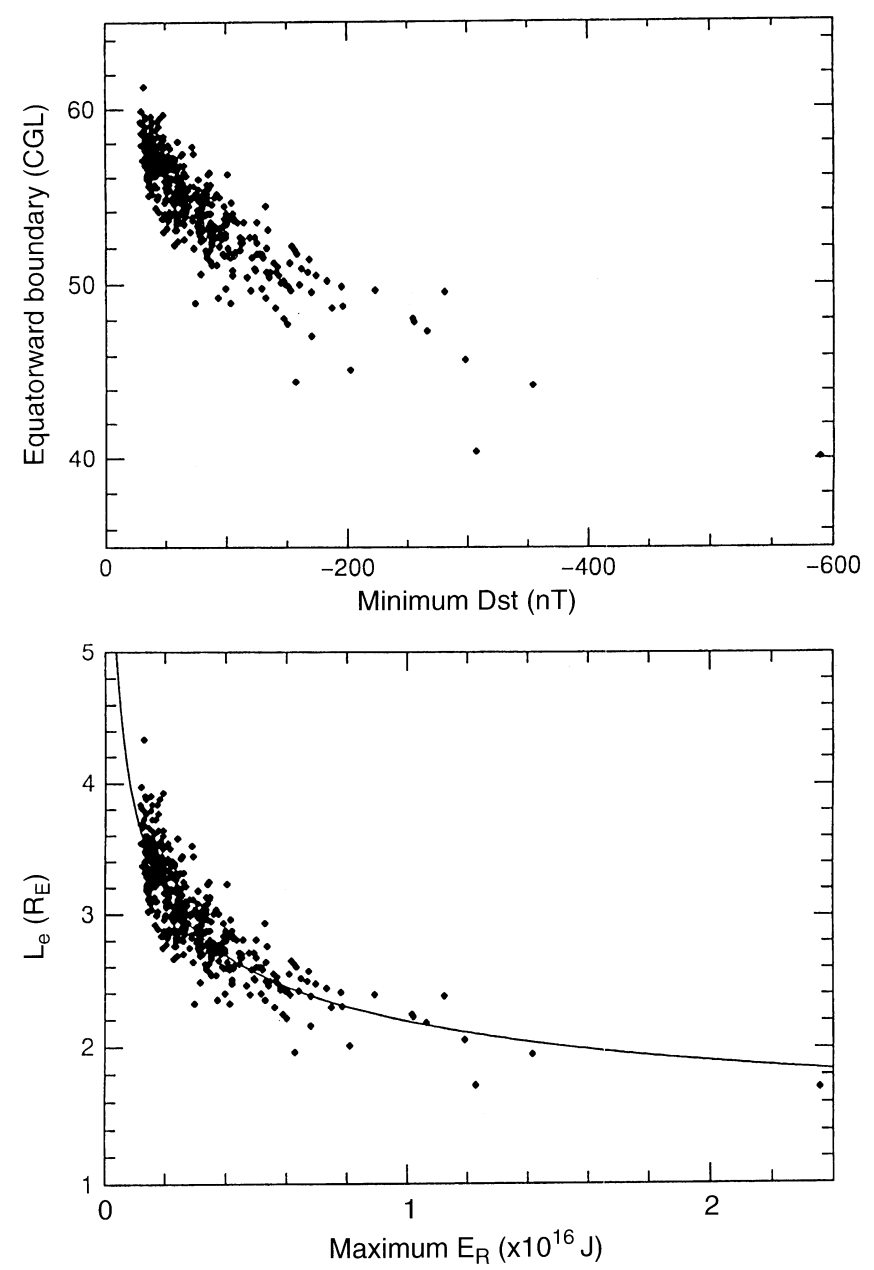

Fig. 3. Top the relationship between the minimum $D s t$ value and the equatorwardmost latitude of the auroral belt boundary for all 423 storms. Bottom the relationship between the ring current energy and the $L$-value corresponding to the auroral boundary. The regression curve indicates the relation $L_{e}^{-3} \propto E_{R}$ proportional to $L_{e}^{-3}$. The $L_{e}^{-3}$ dependence corresponds to the energy gain of plasma particles drifting earthward while their first adiabatic invariant, i.e., their magnetic moment is presented. Accordingly, the $L_{e}^{-3}$ dependence is due to the variation of the dipole field strength on the equatorial plane. The regression curve in the diagram shows the relation $L_{e}^{-3} \propto E_{R}$.

How does the auroral boundary respond to progressive changes in the Dst index, or in the ring current energy, during individual magnetic storms? Figure 4 shows one such example for a very intense storm that occurred on March 13-14, 1989 using the same format as that in Fig. 3; points are shown for the main phase and the recovery phase separately. It is interesting to see in Fig. 3 and 4 that the statistical relationship for peak Dst values of a number of storm events and the relationship between the auroral boundary and changing Dst values in the course of an individual storm are quite similar, as far as the main phase (circles in Fig. 4) is concerned. It is noteworthy, however, that the relationship between the auroral boundary and $D s t$ for
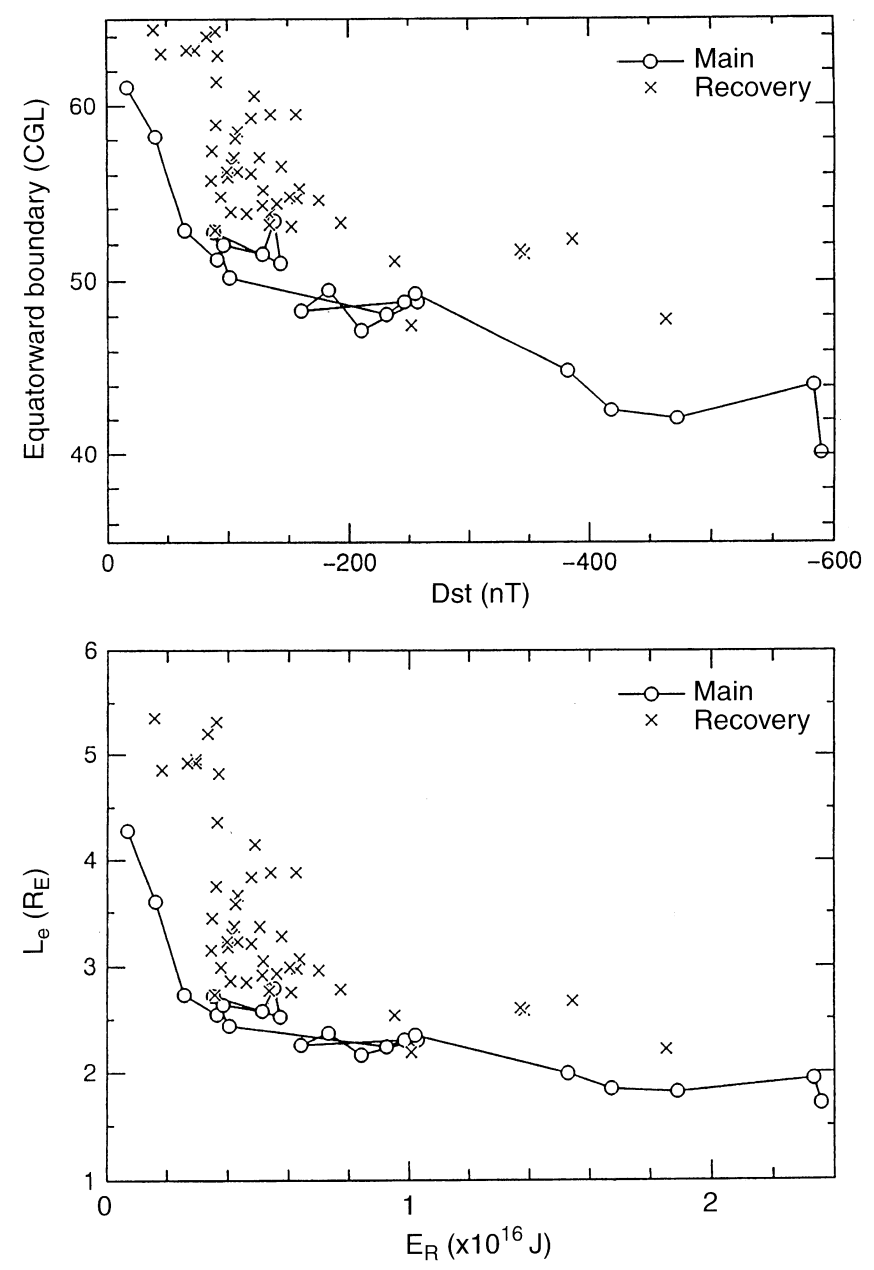

Fig. 4. Top correlation between the ring current energy and the boundary index for the very intense storm of March 13-14, 1989. Bottom open circles and crosses show the main phase and recovery phase, respectively. For the main phase (shown by open circles), the time development is traced by connecting two adjacent points 
the recovery phase is quite different from that for the main phase.

\subsection{The ring current and magnetospheric magnetic field}

The ring current is formed by trapped energetic particles, of which total energy can be estimated from using Eq. (1). In reference to the formula by Dessler and Parker (1959) and Sckopke (1966), we have attempted to calculate the magnetic field energy external to the sphere with radius $L_{e}$, which is the $L$-value corresponding to the auroral boundary. Assuming that the magnetic field is dipolar, the energy $E_{M}$ can be provided by the following equation

$E_{M}=\frac{4}{3} \pi R_{E}^{3} \frac{B_{0}^{2}}{\mu_{0}} L_{e}^{-3}=E_{m} L_{e}^{-3}$

where $R_{E}$ is the Earth's radius and $\mu_{0}$ is the magnetic permiability in vacuum, (see Eq. 1 for $B_{0}$ and $E_{m}$.) This leads to

$E_{M}=8 \times 10^{17} L_{e}^{-3}$

where $E_{M}$ and $L_{e}$ are given in $\mathrm{J}$ and $R_{E}$, respectively.

The relationship between the two quantities obtained from Eq. (2) and Eq. (5) is shown in Fig. 5. It yields the statistical result for all magnetic storms that occurred during the period from 1983 to 1991. A linear regression using the least squares method is applied: the correlation coefficient is 0.8 . The regression line $\left(E_{R}=0.11 E_{M}\right.$ $\left.-4.7 \times 10^{14}\right)$ indicates that when $E_{R}=0$ for zero $D s t$, $E_{M}=E_{Q}=4.3 \times 10^{15} \mathrm{~J}$. From Eqs. (3) and (5), it can be seen that the auroral boundary must be located on average, at $65^{\circ}$ during non-storm times. Although we have calculated the energy external to the sphere with $L_{e}$, we need to subtract the effects of the quiet-time energy $E_{Q}$, because we deal only with changes in the magnetic field energy in the near-Earth magnetosphere during magnetic storms. The ratio of $E_{R}$ to $E_{\text {mag }}\left(=E_{M}-E_{Q}\right)$ is

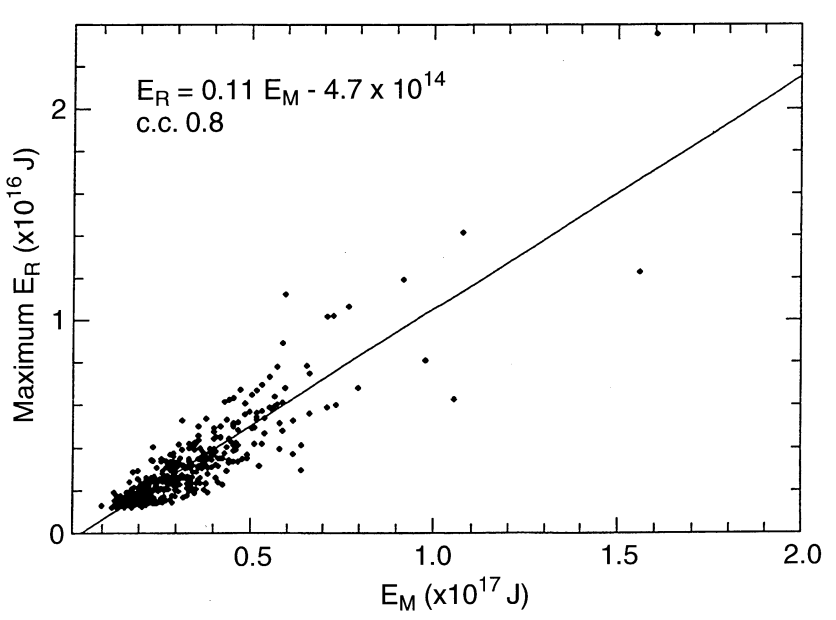

Fig. 5. Correlation between the ring current energy $E_{R}$ and the magnetic field energy $E_{M}$ for all 423 magnetic storms. The fitting line is obtained by the least squares method

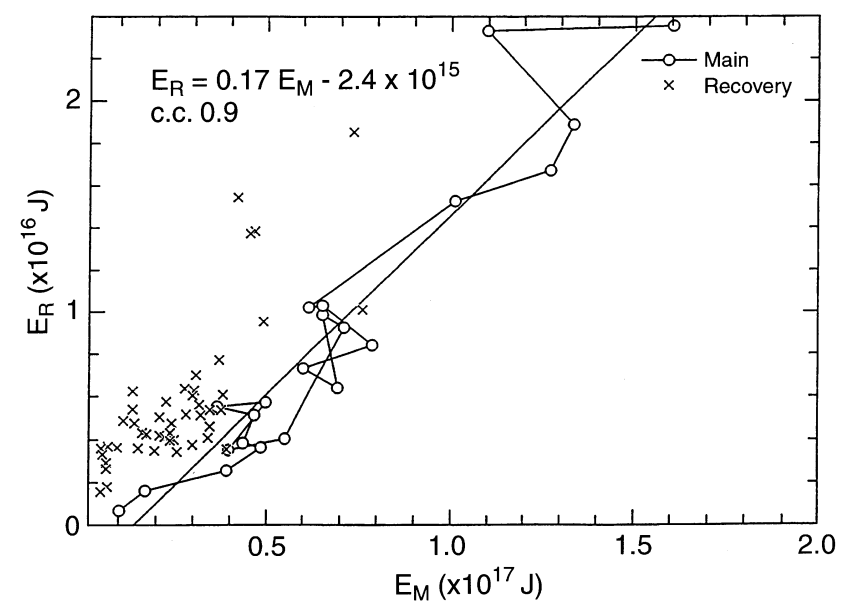

Fig. 6. Correlation between $E_{R}$ and $E_{M}$ for the intense magnetic storm of March 13-14, 1989 in the same format as in Fig. 5. The fitting line for the main phase is obtained by the least squares method. Time tracing lines similar to those in Fig. 4 are drawn for the main phase observations

0.11 ; that is, $11 \%$, on average, of the total magnetic energy $E_{m a g}$ is equal to the ring current energy.

Similarly, Fig. 6 shows the relationship between $E_{R}$ and $E_{M}$ during the very intense storm of March 13 and 14, 1989. Open circles and crosses represent the corresponding values for the main and recovery phases, respectively. The linear regression for the main phase, obtained by the same method as that in the statistical study, is given, although $E_{Q}\left(=1.4 \times 10^{16} \mathrm{~J}\right)$ for this storm is somewhat greater than that in Fig. 5: the main phase of this storm did not commence from $D s t=0$. Note, however, that a lower $E_{Q}$ value can be expected if the $E_{Q}$ value is estimated using the data only at the beginning of the main phase. In this particular case, the ratio of $E_{R}$ to $E_{\text {mag }}$ is 0.17 ; that is, $17 \%$ of the magnetic field energy $E_{\text {mag }}$ is consumed in the ring current. By contrast, the relationship between $E_{R}$ and $E_{M}$ fluctuates considerably during the recovery phase. This implies that the recovery phase of a magnetic storm includes some complicated dissipation processes in the magnetosphere.

\section{Discussion}

Using a data set of geomagnetic storms for the period from 1983 to 1991, we have shown in the present study that changes in the auroral boundary index follow very closely those in the Dst index. The energy of the ring current calculated from the Dst index is found to correlate with $L_{e}^{-3}$, where $L_{e}$ is the $L$-value corresponding to the equatorward boundary of the auroral belt.

\subsection{Ring current energy}

The boundary index monitors the equatorward boundary of the diffuse aurora. It is generally assumed that electron precipitation in the diffuse aurora originates in 
the central plasma sheet (CPS) (Winningham et al., 1975; Makita and Meng, 1984) and that its equatorward boundary is regarded as the zero-energy Alfvén layer, i.e., the inner edge of the CPS (e.g., Frank, 1971; Kamide and Winningham, 1977). The equatorward shift of the diffuse auroral boundary examined in the present study, or the earthward shift of the inner edge of the CPS, represents, directly or indirectly, changes in the magnetospheric configuration as a result of the dayside merging, plasma entry into the magnetosphere, and field line stretching caused by the intense ring current. Siscoe and Cummings (1969), Nakai et al. (1986), and Alexeev et al. (1996) have shown that the shift in the earthward edge of the plasma sheet is controlled primarily by two forces: (1) the balance of the solar wind dynamic pressure and the tail lobe magnetic pressure, and (2) the dawn-to-dusk electric field.

Along with the earthward shift of the electron boundary, ions also penetrate into the near-Earth region, forming the ring current. Since the main phase of magnetic storms takes, several hours at least to grow, which is much longer than the gyration period of ions, one can assume that the first adiabatic invariant, i.e., the magnetic moment, is conserved for penetrating ions. That is,

$\frac{\mathscr{E}_{k}}{B}=$ constant

where the kinetic energy of ions and the magnetic field are $\mathscr{E}_{k}$ and $B$, respectively. Since the dipole magnetic field $B$ is proportional to $L^{-3}$, ions injected in the CPS gain the energy proportional to $L_{e}^{-3}$. Since this energy gain corresponds to the ring current energy, it may well be that the ring current energy is proportional to $L_{e}^{-3}$.

We have found in Fig. 5 and 6 that typically about $10 \%$ of the magnetospheric magnetic energy $E_{\text {mag }}$ is equal to the ring current energy. It is also noted that the ratio of the ring current energy $E_{R}$ to the total magnetic field energy $E_{m a g}$ reaches nearly $20 \%$ for very intense storms. This means that the magnetic energy contained in the spherical shell bounded by $L_{e}$ and $L_{e q}$, where $L_{e q}$ represents quiet-time $L_{e}$, is used as the ring current energy. This "virtual" sphere is not based only on a mathematical simplification but is also physically useful. The near-Earth magnetosphere is approximated by the dipole field and the penetration of plasma particles (electrons in this case) into the near-Earth region requires higher energy against the stronger magnetic field.

What are the implications of the $10-20 \%$ energy? It is important to point out that the magnetic field energy $E_{\text {mag }}$ obtained in our calculation does not take the effect of the "changing" the ring current into account, but is calculated for simplicity under the constant dipole moment. The Earth's dipole moment, however, actually increases by an increase in the ring current, thereby driving magnetospheric inflation. According to Oguti (1995), a 100- $200 \mathrm{nT}$ decrease in Dst probably causes a $7-20 \%$ inflation of the dayside magnetosphere. Our $10 \%$ estimate confirms such a result.

\subsection{Comparison with earlier studies}

Figure 7 presents schematically the location of the auroral belt as a function of Dst from Akasofu and Chapman (1963), and Schulz (1997), compared with the results of the present study. All these three studies treat the ring current intensity measured by $D s t$ as the major contributor to changes in the equatorward boundary of the auroral belt.

On the basis of a simple calculation of the uniform southward IMF and the Earth's dipole field, Schulz (1997) has recently suggested that the polar cap boundary, i.e., the boundary between closed and open field lines, moves approximately $2.3^{\circ}$ equatorward for each $100 \mathrm{nT}$ decrease in Dst. Instead of real Dst data, Schulz (1997) used $B_{01}+\Delta B_{z}$ and $B_{01}+\Delta B_{t}$, where $B_{01}, \Delta B_{z}$, and $\Delta B_{t}$ represent the Earth's surface field obtained from superposition of the dipole magnetic field and the uniform southward IMF without assuming any extraterrestrial currents; the ring current field calculated by an emperical model; and storm time increase of the tail current field, respectively. According to Schulz (1997), $-120 \mathrm{nT}$ in $D s t$ corresponds to $-85 \mathrm{nT}$ in $B_{01}+\Delta B_{z}$ and $-140 \mathrm{nT}$ in $D s t$ corresponds to $-100 \mathrm{nT}$ in $B_{01}+\Delta B_{t}$. For simplicity, the boundary value of Schulz (1997) is shifted equatorward by $10^{\circ}$ since Schulz (1997)'s values relate to the poleward boundary of the auroral belt.

By using all sky cameras and ground magnetometers during "quiet" periods (i.e., when no substorm was in progress) during magnetic storms, Akasofu and Chapman (1963) have shown a $2.5^{\circ}$ equatorward shift of the equatorwardmost arcs for each $100 \mathrm{nT}$ decrease in Dst.

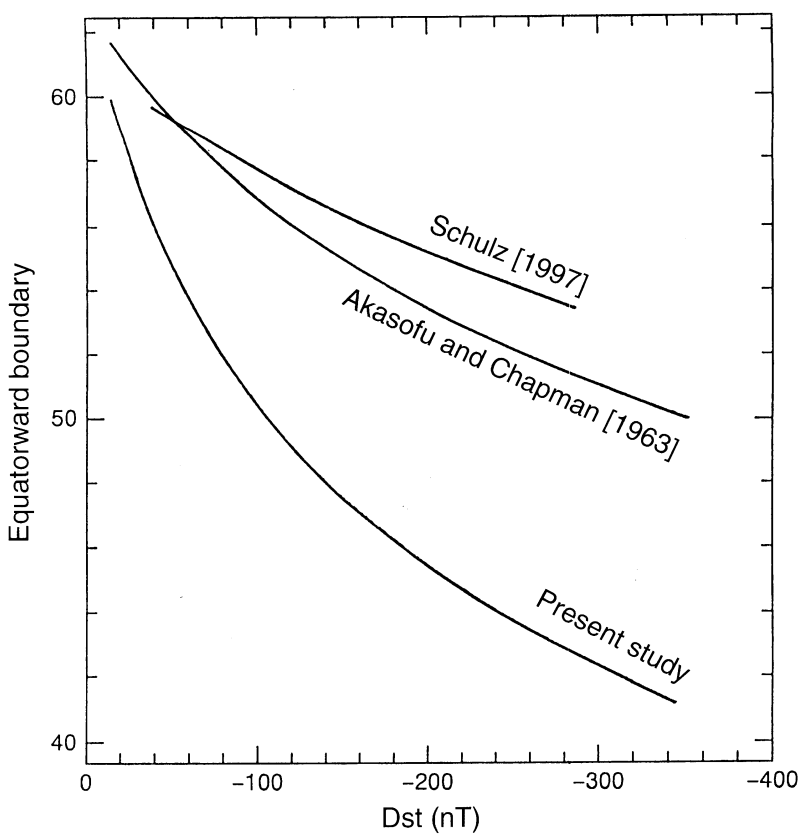

Fig. 7. Three boundaries defined by different conditions as functions of $D s t$ : the equatorward boundary of discrete aurora in Akasofu and Chapman (1963), the boundary between open and closed field lines in Schulz (1997), and electron boundary in the present study respectively. Schulz's boundary value is shifted equatorward by $10^{\circ}$ because his boundary values are for the poleward boundary 
On the other hand, our present study indicates that the equatorward boundary of the auroral belt moves typically $6^{\circ}-7^{\circ}$ equatorward for each $100 \mathrm{nT}$ decrease when the Dst becomes less than $-100 \mathrm{nT}$.

The general trend of the equatorward expansion of the auroral belt with a $D s t$ increase is seen in all the three curves. However, there is a notable discrepancy between the result of Schulz (1997) and ours. It is particularly interesting because it points out either that Schulz (1997) underestimates the expansion of the auroral belt, or that we should invoke somewhat different behavior between the poleward and equatorward boundaries of the nightside auroral belt. Akasofu and Chapman (1963), who have used the equatorward boundary of the discrete aurora when no substorm was in progress, found results that are similar to the theoretical curve of Schulz (1997), but different from ours. The point is that Schulz (1997) and Akasofu and Chapman (1963) did not take substorm effects into account even though intense substorms occur frequently during the storm main phase (e.g., Davis and Parthasarathy, 1967; Loewe and Prölss, 1997). Kamide and Winningham (1977) showed statistically that the equatorward boundary of the nightside auroral belt during substorms is located more equatorward than that which the IMF predicts.

We have also shown that a time lag of one hour exists for Dst to reach the minimum against the time of the lowest latitude of the auroral boundary. This is similar to the time lag between $A E$ and Dst obtained by, for example, Davis and Parthasarathy (1967) and Loewe and Prölss (1997). During a magnetic storm the $A E$ index tends to reach the peak approximately one hour before the corresponding $D s t$ peak: the $A E$ peak results from the frequent occurrence of intense substorms during the storm main phase. Our result for the time lag of about one hour, therefore, implies that the auroral boundary expands equatorward in conjunction with an increase in auroral electrojet activity. It seems likely that long time scale ( $>$ several hours) changes in the location of the auroral belt do reflect the storm effect indicated by the Dst index, whereas substorm effects account for the short time scale ( $1-2 \mathrm{~h})$ contribution, appearing in the $\Lambda$-Dst relationship as the $1-\mathrm{h}$ time lag.

\subsection{Recovery phase}

The present study also points out that a somewhat different quantitative relationship between the size of the auroral belt and the ring current intensity is applicable to the recovery phase: see Fig. 4, 6. We interpret our result for the main phase, namely $E_{R} \propto L_{e}^{-3}$, in terms of the conservation of the first adiabatic invariant. As seen in Fig. 6, however, the $\Lambda$-Dst relationship during the recovery phase is quite complicated, varying considerably from storm to storm. The recovery of magnetic storms does not mean a simple return of the ring current to the pre-storm level. A magnetic storm is a irreversible process.

The different $\Lambda$-Dst relationship between the main and recovery phases must be associated with either the difference in time scales of the expansion and contraction of the auroral oval, or some unique processes during the recovery phase, or both. The auroral oval expands equatorward quickly while it contracts poleward slowly. Nakai et al. (1986) have discussed that the slower contraction of the auroral oval when the IMF has become directed northward might be accounted for by pitch angle diffusion processes (the region of which travels tailward) and/or by the tailward retreat of the CPS inner edge.

Finally, we note that to discuss the $\Lambda-D s t$ relationship properly for the recovery phase, we must take into consideration various processes such as charge exchange (e.g., Smith and Bewtra, 1978) and wave-particle interactions (e.g., Thorne and Horne, 1994). These processes render the relationship between the auroral boundary index and Dst complicated during the recovery phase of magnetic storms. Furthermore, the recovery phase, governed by the ring current loss process, may also be dependent on how the ring current has developed during the main phase (Gleisner et al., 1996). That is, how the ring current recovers to the pre-storm level depends on many factors, including the composition of ring current particles and the location of the ring current.

Acknowledgements. We would like to thank F. J. Rich, M. S. Gussenhoven, D. A. Hardy, and the staff of the Air Force Phillips Laboratory for making the auroral boundary index available. We also thank L. F. Bargatze and K. Shiokawa for their useful discussions throughout the work reported in this paper. The Dst index used in this study was provided by the World Data Center C2 at Kyoto University.

Topical Editor K.-H. Glaßmeier thanks H. Gleisner and G. Prölss for their help in evaluating this paper.

\section{References}

Akasofu, S.-I., The latitudinal shift of the auroral belt, J. Atmos. Terr. Phys., 26, 1167-1174, 1964.

Akasofu, S.-I., and S. Chapman, The lower limit of latitude (US sector) of northern quiet auroral arcs, and its relation to $\operatorname{Dst}(H)$, J. Atmos. Terr. Phys., 25, 9-12, 1963.

Alexeev, I. I., E. S. Belenkaya, V. V. Kalegaev, Y. I. Feldstein, and A. Grafe, Magnetic storms and magnetotail currents, $J$. Geophys. Res., 101, 7737-7747, 1996.

Allen, J., L. Frank, H. Sauer, and P. Reiff, Effects of the March 1989 solar activity, Eos Trans. AGU, 70, 1479, 1989.

Burton, R. K., R. L. McPherron, and C. T. Russell, An empirical relationship between interplanetary conditions and Dst, J. Geophys. Res., 88, 4204-4214, 1975.

Davis, T. N., and R. Parthasarathy, The relationship between polar magnetic activity DP and growth of the geomagnetic ring current, J. Geophys. Res., 72, 5825-5836, 1967.

Dessler, A. J., and E. N. Parker, Hydromagnetic theory of geomagnetic storms, J. Geophys. Res., 64, 2239-4214, 1959.

Frank, L. A., Relationship of the plasma sheet, ring current, trapping boundaries and plasma-pause near the magnetic equator and local midnight, J. Geophys. Res., 76, 2265-2275, 1971.

Gleisner, H., H. Lundstedt, and P. Wintoft, Predicting geomagnetic storms from solar-wind data using time-delay neural networks, Annales Geophysicae, 14, 679-686, 1996.

Gonzalez, W. D., J. A. Joselyn, Y. Kamide, H. W. Kroehl, G. Rostoker, B. T. Tsurutani, and V. M. Vasyliunas, What is a geomagnetic storm?, J. Geophys. Res., 99, 5771-5792, 1994. 
Gussenhoven, M. S., D. A. Hardy, and W. J. Burke, DMSP/F2 electron observations of equatorward auroral boundaries and their relationship to magnetospheric electric fields, J. Geophys. Res., 86, 768-778, 1981.

Gussenhoven, M. S., D. A. Hardy, and N. Heinemann, Systematics of the equatorward diffuse auroal boundary, J. Geophys. Res., 88, 5692-5708, 1983.

Hardy, D. A., W. J. Burke, M. S. Gussenhoven, N. Heinemann, and E. Holeman, DMSP/F2 electron observations of equatorward auroral boundaries and their relationship to the solar wind velocity and the north-south component of the interplanetary magnetic field, J. Geophys. Res., 86, 9961-9974, 1981.

Kamide, Y., Is substorm occurrence a necessary condition for a magnetic storm? J. Geomagn. Geoelectr., 44, 109-117, 1992.

Kamide, Y., and J. D. Winningham, A statistical study of the 'instantaneous' nightside auroral oval: the equatorward boundary of electron precipitation as observed by the Isis 1 and 2 satellites, J. Geophys. Res., 82, 5573-5588, 1977.

Kokubun, S., Relationship of interplanetary magnetic field structure with development of substorm and storm main phase, Planet. Space Sci., 20, 1033-1049, 1972.

Loewe, C. A., and G. W. Prölss, Classification and mean behavior of magnetic storms, J. Geophys. Res., 102, 14209-14214, 1997.

Makita, K., and C.-I. Meng, Average electron precipipation patterns and visual aurora characteristics during geomagnetic quiescence, J. Geophys. Res., 89, 2861-2872, 1984.

Nakai, H., Y. Kamide, D. A. Hardy, and M. S. Gussenhoven, Time scales of expansion and contraction of the auroral oval, $J$. Geophys. Res., 91, 4437-4450, 1986.

Oguti, T., Magnetosphere inflation due to equatorial ring current, J. Geomagn. Geoelectr., 47, 347-352, 1995.

Rassoul, H. K., R. P. Rohrbaugh, and B. A. Tinsley, Low-latitude particle precipitation and associated local magnetic disturbances, J. Geophys. Res., 97, 4041-4052, 1992.
Russell, C. T., R. L. McPherron, and R. K. Burton, On the cause of geomagnetic storms, J. Geophys. Res., 79, 1105-1109, 1974.

Sckopke, N., A general relation between the energy of trapped particles and the disturbance field near the Earth, J. Geophys. Res., 71, 3125-3130, 1966.

Schulz, M., Direct influence of ring current on auroral-oval diameter, J. Geophys. Res., 102, 14149-14154, 1997.

Shiokawa, K., K. Yumoto, C.-I. Meng, and G. Reeves, Broadband electrons observed by the DMSP satellites during storm-time substorms, Geophys. Res. Lett., 23, 2529-2532, 1996.

Siscoe, G. L., and W. D. Cummings, On the cause of geomagnetic bays, Planet. Space Sci., 17, 1795-1802, 1969.

Smith, P. H., and N. K. Bewtra, Charge exchange lifetimes for ring current ions, Space Sci. Rev., 22, 301-318, 1978.

Sugiura, M., and S. Chapman, The average morphology of geomagnetic storms with sudden commencement, Abh. Akad. Wiss. Göttingen Math. Phys. Kl., 4, 1-53, 1960.

Sugiura, M., and T. Kamei, Equatorial Dst index 1957-1986, IAGA Bull., 40, 1991.

Taylor, J. R., M. Lester, and T. K. Yeoman, A superposed epoch analysis of geomagnetic storms, Annales Geophysicae, 12, 612624, 1994.

Thorne, R. M., and R. B. Horne, Energy transfer between energetic ring current $\mathrm{H}^{+}$and $\mathrm{O}^{+}$by electromagnetic ion cyclotron waves, J. Geophys. Res., 99, 17,275-17,282, 1994.

Tinsley, B. A., R. Rohrbaugh, H. Rassoul, Y. Sahai, N. R. Telxeira, and D. Slater, Low-latitude aurorae and storm time current systems, J. Geophys. Res., 91, 11257-11269, 1986.

Winningham, J. D., F. Yasuhara, S.-I. Akasofu, and W. J. Heikkila, The latitudinal morphology of $10-\mathrm{eV}$ to $10-\mathrm{keV}$ electron fluxes during magnetically quiet and disturbed times in the 2100-0300 MLT sector, J. Geophys. Res., 80, 3148-3171, 1975.

Yokoyama N., and Y. Kamide, Statistical nature of geomagnetic storms, J. Geophys. Res., 102, 14215-14222, 1997. 